\title{
Analysis of Consumer Repurchase Intention towards Online Shopping in Indonesia's Online Retail Business Market
}

\author{
Mathias Dharmawirya and Bintang A. Smith
}

\begin{abstract}
Factors affecting repurchase intention have been investigated by many prior studies. However, the study towards online shopping repurchase intention and specifically in the Indonesia region has not been studied. An empirical study was conducted to investigate and identify the key factors that make customers willing to repurchase through online shopping. We evaluated some theories that have been used to investigate repurchase intentions and proposed a modified framework and develop our hypotheses. Our results pointed that Performance Expectancy and Facilitating Conditions to be the two most important factors that will influence the repurchase intention of customers. The implications of the findings were also discussed.
\end{abstract}

Index Terms-E-commerce, online shopping, repurchase intention, UTAUT.

\section{INTRODUCTION}

The establishment of online stores has changed the way customers think and behave towards purchasing decision. It undoubtedly has delivered numerous advantages allowing customers to purchase and acquire product easily and effortlessly without having to visit physical stores. However, there are also several major concerns that come along with the flexibility and convenience offered by Internet technology. When customers go to a physical store, they can experience and feel what the product is like. Moreover, customers can also pay by cash. Even if they suddenly feel like to choose another payment method like by using debit or credit card, it is almost certainly still safer since the customers is involved and can watch over the whole payment process. In contrast, when the customers visit an online store to purchase a product, they will not be able to touch and feel what the product is really like. Then, when it comes to the payment decision, it is a really big security concern whether the online store can be trusted or not since most online stores are using credit card payment method instead of cash [1].

This paper intends to figure out the most influential factors of consumer repurchase intention towards online shopping in Indonesia's B2C e-commerce environment especially for online retail business market. Because of that particular reason, this research will be directed to the evaluation and analysis of consumer repurchase intention towards two of the biggest Indonesia's online retail businesses which are

Manuscript received May 10 2012; revised June 82012.

M. Dharmawirya is with the School of Information Systems, Binus International, Binus University, Jakarta 10270, Indonesia (e-mail: mdharmawirya@binus.edu).

B. A. Smith was with the School of Information Systems, Binus International, Binus University, Jakarta, Indonesia.
Bhinneka.com and GlodokShop.com.

\section{THEORETICAL BACKGROUND}

Repurchase intention at online shops have been investigated by researchers using many different theories such as Theory of Reasoned Action [2], Technology Acceptance Model [3], Expectation Confirmation Theory [4] and Unified Theory of Acceptance and Use of Technology [5].

Theory of Reasoned Action, or TRA, is a theory to predict a wide range of behaviors. The core constructs of TRA are Attitude toward Behavior and Subjective Norm. TRA was adapted by Fishbein and Ajzen to study individual acceptance of technology [6].

Technology Acceptance Model, or TAM, is an adaptation of TRA by Fred D. Davis to predict information technology acceptance and usage on the job. TAM does not include attitude construct like TRA in order to better explain intention parsimoniously. The core constructs of TAM are Perceived Usefulness, Perceived Ease of Use, and Subjective Norm [7].

Expectation Confirmation Theory, or ECT, suggests that confirmation and user satisfaction are the primary determinants of repurchase intention as suggested by Bhattacherjee [8]. Confirmation indicates the evaluation of customers regarding the perceived performance as compared to their original expectation about a certain product. Confirmation will subsequently influence customers' satisfaction level [4].

Unified Theory of Acceptance and Use of Technology, or UTAUT, is a theory to help researcher in studying consumer intentions and following behavior towards usage of an information system proposed by Venkatesh [9]. It has two main dependent constructs and eight independent constructs consisting of four key constructs and four moderators of key constructs. The dependent constructs of UTAUT are Behavioral Intention and Usage Behavior. Both of these dependent constructs will be directly affected and determined by the four key constructs which are Performance Expectancy, Export Expectancy, Social Influence, and Facilitating Conditions. The impacts of four key constructs mentioned previously will be moderated by Gender, Age, Experience, and Voluntariness of Use. This theory was developed through evaluation and consolidation of eight research models' constructs within the same research nature. Those models are Theory of Reasoned Action (TRA), Technology Acceptance Model (TAM), Motivational Model (MM), Theory of Planned Behavior (TPB), aCombined 
Theory of Planned Behavior/Technology Acceptance Model (C-TAM-TPB), Model of PC Utilization (MPCU), Innovation Diffusion Theory (IDT), and Social Cognitive Theory (SCT) [9].

\section{RESEARCH MODEL AND HYPOTHESES}

There are eleven hypotheses formulated for this thesis based on the dependent and independent variables of modified UTAUT. Modified version of UTAUT will be used for the specific purpose of analyzing consumer repurchase intention towards online shopping.

There is only one main dependent variable in this modified version of UTAUT (Repurchase Intention) and eight independent variables consisting of four key constructs (Performance Expectancy, Effort Expectancy, Social Influence, and Facilitating Conditions) and four moderators of key constructs (Gender, Age, Experience, and Voluntariness of Use) as summarized in Fig. 1.

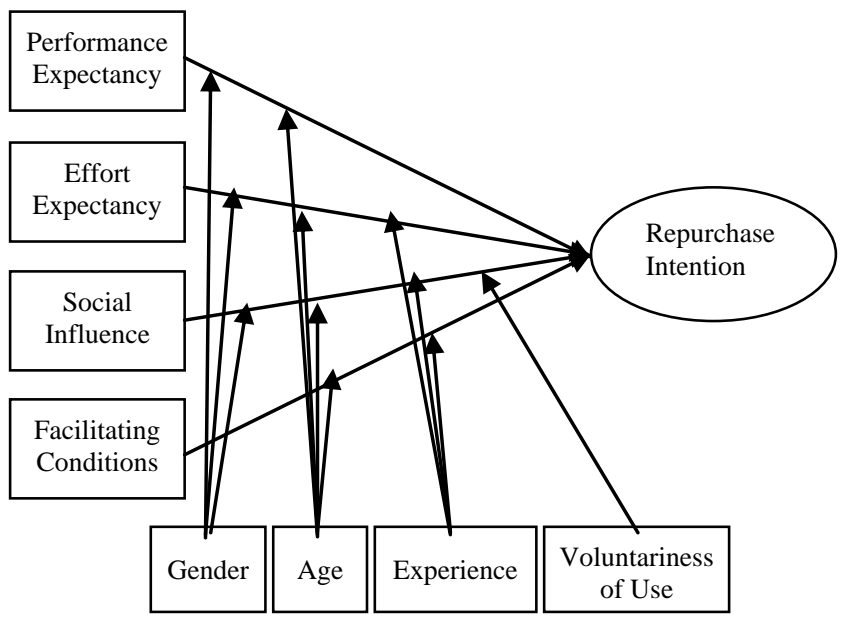

Fig. 1. Research model.

\section{A. Performance Expectancy}

Performance Expectancy is the degree to which an individual believes that using the system will help him or her to attain gains in job performance [9]. To put it differently, this construct measures how far an individual believes that the system can perform to satisfy his or her requirements:

- H0a: Performance Expectancy moderated by Gender is not influencing repurchase intention towards online shopping.

- H1a: Performance Expectancy moderated by Gender is influencing repurchase intention towards online shopping.

- H0b: Performance Expectancy moderated by Age is not influencing repurchase intention towards online shopping.

- H1b: Performance Expectancy moderated by Age is influencing repurchase intention towards online shopping.

\section{B. Effort Expectancy}

Effort Expectancy is the degree of ease associated with the use of the system.In other words, this construct measures how complex it is for an individual to use a particular system [9].
- H0c: Effort Expectancy moderated by Gender is not influencing repurchase intention towards online shopping.

- H1c: Effort Expectancy moderated by Gender is influencing repurchase intention towards online shopping.

- H0d: Effort Expectancy moderated by Age is not influencing repurchase intention towards online shopping.

- H1d: Effort Expectancy moderated by Age is influencing repurchase intention towards online shopping.

- H0e: Effort Expectancy moderated by Experience is not influencing repurchase intention towards online shopping.

- H1e: Effort Expectancy moderated by Experience is influencing repurchase intention towards online shopping.

\section{Social Influence}

Social Influence is the degree to which an individual perceives that important others believe he or she should use the new system [9]. That is to say, this construct measures how far an individual sees that social environment can affect him or her to use a particular system.

- HOf: Social Influence moderated by Gender is not influencing repurchase intention towards online shopping.

- H1f: Social Influence moderated by Gender is influencing repurchase intention towards online shopping.

- H0g: Social Influence moderated by Age is not influencing repurchase intention towards online shopping.

- H1g: Social Influence moderated by Age is influencing repurchase intention towards online shopping.

- H0h: Social Influence moderated by Experience is not influencing repurchase intention towards online shopping.

- H1h: Social Influence moderated by Experience is influencing repurchase intention towards online shopping.

- H0i: Social Influence moderated by Voluntariness of Use is not influencing repurchase intention towards online shopping.

- H1i: Social Influence moderated by Voluntariness of Use is influencing repurchase intention towards online shopping.

\section{Facilitation Conditions}

Facilitating Conditions is the degree to which an individual believes that an organizational and technical infrastructure exists to support use of the system [9]. In other words, this construct measures how far an individual believes that he or she will get facilitation for the system from existing infrastructures:

- H0j: Facilitating Conditions moderated by Age is not influencing repurchase intention towards online shopping.

- H1j: Facilitating Conditions moderated by Age is 
influencing repurchase intention towards online shopping.

- H0k: Facilitating Conditions moderated by Experience is not influencing repurchase intention towards online shopping.

- H1k: Facilitating Conditions moderated by Experience is influencing repurchase intention towards online shopping.

\section{RESEARCH METHOD}

The data was obtained by conducting a random survey through individual questionnaires. We collected data from 100 users of online shopping in Indonesia who have repurchased online at least once at Bhinneka.com or GlodokShop.com. $85 \%$ of the respondents were male and $89 \%$ of them were below 35 years old.

The questionnaire consists of questions on the demographics of the respondents and questions on the dependent variable and four key constructs. All factors were measured using 6-point Likert scales.

Data analysis is done in several steps. First, all data were saved in Microsoft Excel format. Next, the data is processed using descriptive statistic technique to produce a basic summary and description from data interpretation. There are four variables that will be processed and analyzed using descriptive statistic technique. These variables are Gender, Age, Experience, and Voluntariness of Use. After that, all of the independent variables including the key constructs moderator are analyzed using inferential statistic technique namely the linear regression. SPSS will be used to do the statistical analysis to find out whether there is any correlation between each variables and whether there is any impact from the moderators to the key constructs.

\section{V.RESULTS AND FINDINGS}

\section{A. Descriptive Statistics}
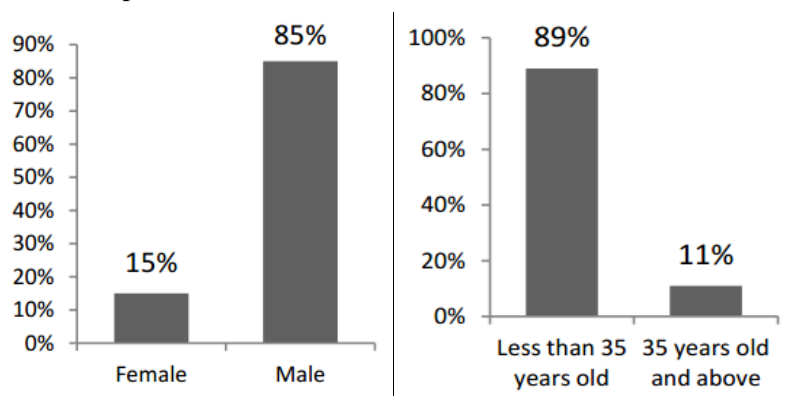

Fig. 2. Respondents' gender.

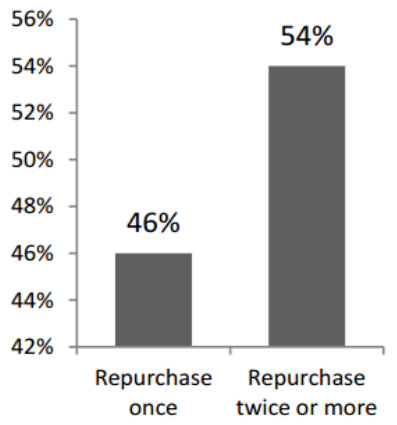

Fig. 4. Respondents' experience

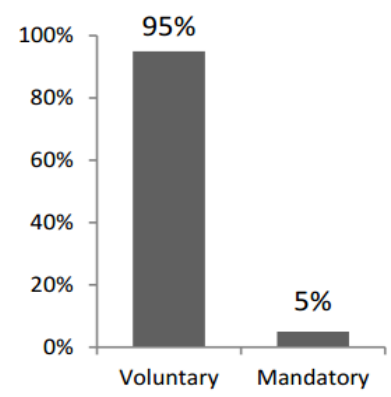

Fig. 5. Respondents' voluntariness of use.

Fig 2. to Fig. 5. summarize the demography of our respondents. It can be seen that most of the respondents were young males who voluntarily repurchase at either Bhinneka.com or GlodokShop.com and more than $50 \%$ have actually done multiple repurchases at either of the online shops.

\section{B. Inferential Statistics}

Table I summarizes the correlation between key constructs of modified UTAUT towards Repurchase Intention, while Table II summarizes the correlation of key constructs with moderation from Gender, Age, Experience, and Voluntariness of Use. First of all, it is shown in Figure 31 that Performance Expectancy plays the most important role in influencing someone to repurchase from online retail business. Performance Expectancy derived from the questionnaires by evaluating website interactivity, payment flexibility, products price, products needs fulfillment, and accuracy if products information.

Facilitating Conditions is following right behind Performance Expectancy as the second most influential factor in affecting repurchases intention. It is evaluated by education level, income level, website security, and internet connection.

Effort Expectancy also has correlation towards Repurchase Intention which is right under Facilitating Conditions and it is evaluated by ease of use.

However, Social Influence does not seem to have any influence towards Repurchase Intention.

TABLE I: KEY CONSTRUCTS CORRELATION SUMMARY

\begin{tabular}{lllll}
\hline \hline & $\mathrm{R}^{2}$ & Adjusted $\mathrm{R}^{2}$ & $\mathrm{~F}$ & Sig. \\
\hline \hline $\mathrm{PE}$ & $56.9 \%$ & $56.5 \%$ & 129.509 & 0.000 \\
$\mathrm{EE}$ & $20.6 \%$ & $19.8 \%$ & 25.450 & 0.000 \\
$\mathrm{SI}$ & $2.4 \%$ & $1.4 \%$ & 2.394 & 0.125 \\
$\mathrm{FC}$ & $30 \%$ & $29.3 \%$ & 42.088 & 0.000 \\
\hline
\end{tabular}

Moving on to Table II, it is shown whether a hypothesis is accepted or not. Even though Performance Expectancy moderated by Gender and Age influence Repurchase Intention, they do not give much contribution on the correlation strength of Performance Expectancy.

TABLE II: MODERATORS INFLUENCE SUMMARY

\begin{tabular}{llllll}
\hline \hline & \multicolumn{1}{c}{$\mathrm{R}^{2}$} & $\begin{array}{c}\text { Adjusted } \\
\mathrm{R}^{2}\end{array}$ & $\mathrm{~F}$ & $\mathrm{Sig}$. & $\begin{array}{l}\text { Hypothesis } \\
\text { Acceptance }\end{array}$ \\
\hline \hline PE-G & $57.1 \%$ & $56.2 \%$ & 64.500 & 0.000 & H1a Accepted \\
PE-A & $57.5 \%$ & $56.6 \%$ & 65.501 & 0.000 & H1b Accepted \\
EE-G & $20.7 \%$ & $19.1 \%$ & 12.674 & 0.000 & H1c Accepted \\
EE-A & $21.2 \%$ & $19.5 \%$ & 13.024 & 0.000 & H1d Accepted \\
EE-E & $25.1 \%$ & $23.6 \%$ & 16.280 & 0.000 & H1e Accepted \\
SI-G & $2.7 \%$ & $0.7 \%$ & 1.332 & 0.269 & H0f Rejected \\
SI-A & $2.6 \%$ & $0.6 \%$ & 1.311 & 0.274 & H0g Rejected \\
SI-E & $9.8 \%$ & $8 \%$ & 5.295 & 0.007 & H1h Accepted \\
SI-VOU & $3.8 \%$ & $1.9 \%$ & 1.935 & 0.150 & H0i Rejected \\
FC-A & $30.5 \%$ & $29.1 \%$ & 21.277 & 0.000 & H1j Accepted \\
FC-E & $32.9 \%$ & $31.5 \%$ & 23.803 & 0.000 & H1k Accepted
\end{tabular}

This means the difference whether it is female or male, young or old, only has a slight effect in Performance Expectancy towards Repurchase Intention. 
Gender and Age also do not give much contribution to Effort Expectancy. However, Experience seems to have a noticeable influence on Effort Expectancy towards Repurchase Intention. It makes Effort Expectancy becoming more sensitive when it comes to a different level of experience.

Social Influence, which originally does not have any influence towards Repurchase Intention, unexpectedly becomes influential if Experience is moderating. Someone with lower level of experience might be easier to be influenced by the social environment.

Age only has small effect on Facilitating Conditions, while Experience has noticeable effect as it does to Effort Expectancy and Social Influence. In brief, all hypotheses are accepted, except Social Influence when it is moderated by Gender, Age, and Voluntariness of Use, with Performance Expectancy being the most influential key constructs, while Experience being the most powerful moderator of key constructs.

\section{CONCLUSION}

Online shopping has become an alternative way of shopping in Indonesia especially with the facilitation of widespread Internet technology. Many newcomers are trying to penetrate the online retail business market and struggle with difficulties in order to survive in this competitive market. That is why it is vital to understand what factors are the most important and needed to be implemented on an online store.

This research has revealed that Performance Expectancy is the most crucial factor in order to enhance customer loyalty through repurchase activities. Gender and Age moderate the strength of Performance Expectancy, although it is not really significant. Therefore, online retail businesses should pay more attention in developing the performance of their online stores and make some adjustments to satisfy different kinds of Gender and Age.

Understanding the Facilitating Conditions of the target market, also help the online retail business to influence customers to repurchase. Age and Experience of the customers on the target market should be learned as well in order to better understand Facilitating Conditions.

Furthermore, making an online store easy to use is also important as Effort Expectancy clearly influences Repurchase Intention. Different kinds of Gender, Age, and especially Experience should be taken into account as well to develop an online store that is easy to use. Inexperienced or customers with low level of experience might be easier to be influenced by their surroundings such as friends, families, acquaintances, or relatives. Therefore, it is necessary to develop a strong and good brand image.

For future research, it is recommended to prepare more time to conduct research and if possible, samples should be taken from each province in Indonesia. This topic about repurchase intention towards online shopping is really interesting and could be very helpful for new and existing online retail business in Indonesia if the data are more accurate and better processed. Moreover, developing a new framework specific for repurchase intention towards online shopping will also be very advantageous since using UTAUT has proven that Social Influence does not have any influences towards Repurchase Intention, except when moderated by Experience. Conducting several researches on different types of online retail business will produce better understanding also. As a result, the similarities and differences might be revealed between each type of online retail business regarding on what factors influencing consumer repurchase intention.

\section{REFERENCES}

[1] D. Gefen, "E-commerce: the role of familiarity and trust," Omega, vol. 28, no. 6, pp. 725-737, 2000.

[2] H. Lee, S. Y. Choi, and Y. S. Kang, "Formation of e-satisfaction and repurchase intention: Moderating roles of computer self-efficacy and computer anxiety," Expert Systems with Applications, vol. 36, no. 4, pp. 7848-7859, 2009.

[3] C. M. Chiu, C. C. Chang, H. L. Cheng, and Y. H. Fang, "Determinants of customer repurchase intention in online shopping," Online Information Review, vol. 33, no. 4, pp. 761-784, 2009.

[4] K. Atchariyachanvanich, H. Okada, and N. Sonehara, "What keeps online customers repurchasing through the internet?," ACM SIGecom Exchanges, vol. 6, no. 2, pp. 47-57, 2007.

[5] V. Venkatesh, J. Y. L. Thong, F. K. Y. Chan, P. J. H. Hu, and S. A. Brown, "Extending the two-stage information systems continuance model: incorporating UTAUT predictors and the role of context," Information Systems Journal, 2011.

[6] M. Fishbein and I. Ajzen, Belief, attitude, intention and behaviour: An introduction to theory and research. Addison-Wesley, 1975.

[7] F. D. Davis, "Perceived usefulness, perceived ease of use, and user acceptance of information technology," MIS quarterly, pp. 319-340, 1989.

[8] A. Bhattacherjee, "Understanding information systems continuance: An expectation-confirmation model," MIS quarterly, pp. 351-370, 2001.

[9] V. Venkatesh, M. G. Morris, G. B. Davis, and F. D. Davis, "User acceptance of information technology: Toward a unified view," MIS quarterly, pp. 425-478, 2003.

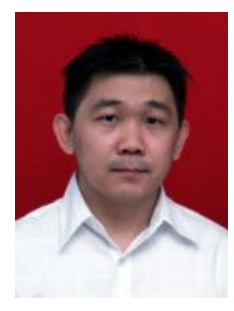

M. Dharmawirya earned his bachelor and master degree from Nanyang Technological University, Singapore. He was a Systems Analyst at Deutsche Bank in Singapore. Currently, he serves as the Program Coordinator of the School of Information Systems of Binus International.

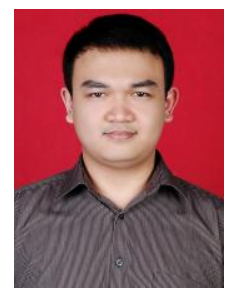

B. A. Smith earned a Bachelor Degree in from the School of Information Systems at Binus International, Binus University, Jakarta, Indonesia. He is currently working at Accenture Jakarta. 